\title{
Isolation and identification of Vibrio parahaemolyticus from seawater and sediment samples in the southern coast of the Caspian Sea
}

\author{
Majid Alipour • Khosro Issazadeh • Javad Soleimani
}

Received: 30 January 2012 / Accepted: 25 July 2012 /Published online: 8 August 2012

(C) The Author(s) 2012. This article is published with open access at Springerlink.com

\begin{abstract}
The objectives of this study were to investigate the occurrence of Vibrio parahaemolyticus in the seawater and its sediment by molecular techniques and conventional microbiological methods. Of 300 samples analyzed, $20.3 \%$ was recorded positive for $V$. parahaemolyticus. Of the 62 strains isolated, $26(8.3 \%)$ were obtained from the seawater samples, and 36 (12\%); from sediments. Only three strains (4.83\%) showed hemolytic activity in Wagatsuma agar. The results of this study demonstrated the presence of $V$. parahaemolyticus in the southern coast of the Caspian Sea (Northern Iran). Furthermore, the PCR approach proved useful for reliable confirmation of species identification. $V$. parahaemolyticus is an important human pathogen responsible for food-borne gastroenteritis worldwide. These findings indicated the potential sanitary risk associated with the presence of pathogenic $V$. parahaemolyticus in the Caspian Sea.
\end{abstract}

Keywords Vibrio parahaemolyticus · Seawater · Sediment . Acute gastroenteritis

\section{Introduction}

Vibrio parahaemolyticus is a human pathogen that is widely distributed in the marine environments. It has a single polar flagellum and is motile when grown in liquid medium (Broberg et al. 2011). V. parahaemolyticus is a marine bacterium easily recovered from estuarine and coastal

\footnotetext{
M. Alipour ( $\square)$

Department of Microbiology, Islamic Azad University (IAU),

Babol Branch, Babol, Iran

e-mail: alipourrna@yahoo.com

K. Issazadeh $\cdot$ J. Soleimani

Department of Microbiology, Islamic Azad University (IAU),

Lahyjan Branch, Lahyjan, Iran
}

waters worldwide, as well as from seawater (Hayat et al. 2006). V. parahaemolyticus requires presence of salinity with optimum levels of $1-3 \%$ to survive and multiply, which is in the range of $0.8-3 \%$ levels commonly found in marine environments (Yeung and Boor 2004). V. parahaemolyticus causes three major syndromes of clinical illness, i.e., gastroenteritis, wound infections, and septicemia. Gastrointestinal illness caused by $V$. parahaemolyticus is typically accompanied by symptoms including vomiting, diarrhea, headache, nausea, low-grade fever, and abdominal cramps, and is commonly self-limiting. The mean incubation period for $V$. parahaemolyticus infection is $15 \mathrm{~h}$ (Nair et al. 2007). Clinical isolates of $V$. parahaemolyticus most often produce either the thermostable direct hemolysin (TDH) or TDH-related hemolysin (TRH) encoded by $t d h$ and $t r h$ genes, respectively. However, only bacteria producing virulence factors, i.e., TDH and/or TRH, are considered to be pathogenic and can cause acute gastroenteritis (or, more rarely, invasive septicemia) (Bisha et al. 2012). TDH is capable of producing $\beta$ hemolysis on Wagatsuma agar which is called Kanagawa phenomenon (KP). Most of the strains (90\%) isolated from clinical cases show this type of hemolysis, while only $1-2 \%$ of the strains of environmental origin are KP positive (Drake et al. 2007). TRH is another virulence factor that has been discovered in clinical strains lacking $t d h$ gene. TRH is a $23-\mathrm{kDa}$ protein, immunologically related to TDH and environmental strains producing this gene, and produces urease (Pal and Das 2010). Epidemiological studies have revealed an association between the Kanagawa phenomenon and gastroenteritis (Okuda et al. 1997). The objectives of the present study are, first, to determine the prevalence of total and pathogenic $V$. parahaemolyticus in seawater and sediment in the southern coast of the Caspian Sea and, second, to investigate the relationships with water temperature and salinity. The strains isolated were screened for hemolytic activity and for the presence of the $t d h$ and $t r h$ genes. A limitation of the 
research was the long distance between the sampling sites and the laboratory.

\section{Materials and methods}

The seawater samples and sediments were collected at a depth of 50 and $10-20 \mathrm{~cm}$, respectively, by aseptic techniques. Of the 300 total samples, 150 seawater and 150 sediment samples were collected from seven different sites in the Caspian Sea in April, May, June, July, and August (Fig. 1).

The samples were placed in sealed containers with dry ice and transported frozen to the laboratory for analysis. The time between sample collection and analysis was approximately $24 \mathrm{~h}$, while sampling, water temperature, and salinity were measured.

\section{V. parahaemolyticus isolation and identification}

Twenty-five milliliters of seawater samples and $25 \mathrm{~g}$ of sediment samples were added to $225 \mathrm{ml}$ of alkaline peptone water (APW) containing $1 \% \mathrm{NaCl}(\mathrm{pH} 8.6$ ), and $10^{-2}$ and $10^{-3}$ APW dilutions were prepared in duplicate and incubated at $37{ }^{\circ} \mathrm{C}$ for $6-24 \mathrm{~h}$. Enrichment broth was streaked onto thiosulfate-citrate-bile salts-sucrose agar plates and incubated at $37{ }^{\circ} \mathrm{C}$ for 18-24 h. The green or blue-green colonies were presumptively selected as $V$. parahaemolyticus colonies and transferred to trypticase soy agar plate containing $3 \%$ $\mathrm{NaCl}$. After incubation at $37{ }^{\circ} \mathrm{C}$ for $24 \mathrm{~h}$, the isolates were tested using conventional bacterial methods, including Gram's staining, culture sulfide indole motility and triple sugar iron tests media, cytochrome oxidase activity tests, lysine iron agar tests, urea tests, and tests for arabinose, lactose, mannitol, mannose, and sucrose fermentation (Colakoglu et al. 2006).

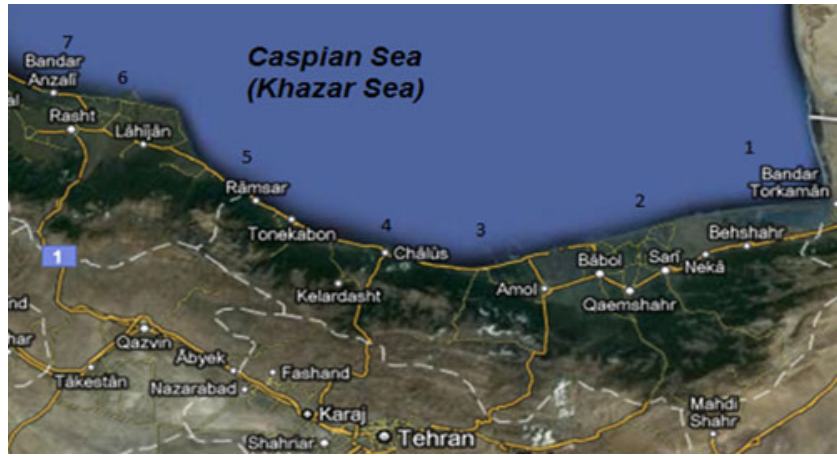

Fig. 1 Area of study and locations of the sampling sites in the southern coast of the Caspian Sea (Northern Iran). Site 1 Bandar Torkaman, site 2 Sari, site 3 Noor, site 4 Chalus, site 5 Ramsar, site 6 Chamkhaleh, site 7 Bandar Anzali
Hemolytic activity

Kanagawa test was performed using Wagatsuma agar supplemented with $5 \%$ human erythrocytes. Each plate was inoculated with $V$. parahaemolyticus strains. Positive reactions were recorded as a zone of $\beta$ hemolysis surrounding the spot of growth on the human blood plate. The interpretation times for the test were 24, 48, and $72 \mathrm{~h}$ (CanizalezRoman et al. 2011).

\section{DNA purification}

V. parahaemolyticus strains were seeded in Luria-Bertani agar supplemented with $1 \% \mathrm{NaCl}$ and incubated at $37^{\circ} \mathrm{C}$ for $24 \mathrm{~h}$. Five colonies were selected, resuspended in $100 \mu \mathrm{l}$ of filtered sterile distilled water, and boiled for 15-20 min to liberate the nucleic acid (Cabrera-Garcia et al. 2004).

Confirmation of strains by polymerase chain reaction

The $t d h$ and $t r h$ genes were amplified with the following primer sets: 5'-GTAAAGGTCTCTGACTTTTGGAC-3' and 5'-TGGAATAGAACCTTCATCTTCACC-3' for $t d h$, and 5'-TTGGCTTCGATATTTTCAGTATCT-3' and 5'CATAACAAACATATGCCCATTTCCC-3' for $t r h$ (Tada et al. 1992). These primer sets produced 251- and 373-bp amplicons, respectively. The reaction mixtures (final volume, $25 \mu \mathrm{l}$ ) contained $3 \mu \mathrm{l}$ of the solution containing DNA, $2.5 \mu \mathrm{l}$ of $10 \times$ reaction buffer, $4 \mu \mathrm{l}$ of $25 \mathrm{mM} \mathrm{MgCl} 2,1 \mu \mathrm{l}$ of Taq polymerase $(5 \mathrm{U} / \mu \mathrm{l}), 4 \mu \mathrm{l}$ of deoxynucleoside triphosphates $(1 \mathrm{Mmol}), 1 \mu \mathrm{l}$ of each primer $(20 \mathrm{pmol})$, and $8.5 \mu \mathrm{l}$ of distilled water. The reactions were performed as follows: initial denaturation at $94{ }^{\circ} \mathrm{C}$ for $1 \mathrm{~min}$, followed by 35 cycles of denaturation at $94{ }^{\circ} \mathrm{C}$ for $1 \mathrm{~min}$, annealing at $55^{\circ} \mathrm{C}$ for $1 \mathrm{~min}$, extension at $72^{\circ} \mathrm{C}$ for $1 \mathrm{~min}$, and a final extension at $72{ }^{\circ} \mathrm{C}$ for $7 \mathrm{~min}$. Positive and negative DNA controls were included in all assays. The amplified products were separated by electrophoresis in ethidium bromide-stained $2 \%$ agarose gels in Tris-borate-EDTA buffer at $120 \mathrm{~V}$ for $30 \mathrm{~min}$. The gels were visualized with a UV transilluminator.

\section{Results}

A total of 300 samples were analyzed; these samples included 150 seawater and 150 sediment samples. Overall, $V$. parahaemolyticus strains were isolated from $20.3 \%$ of the samples (Table 1). The highest isolation rate of $V$. parahaemolyticus was observed in August, with a total of 23 positive samples $(28.3 \%)$. The temperatures ranged between 34 and $39^{\circ} \mathrm{C}$ during the sampling period. By contrast, the lowest isolation rate of $V$. parahaemolyticus was observed in April, with a total of 3 positive samples (5\%). 


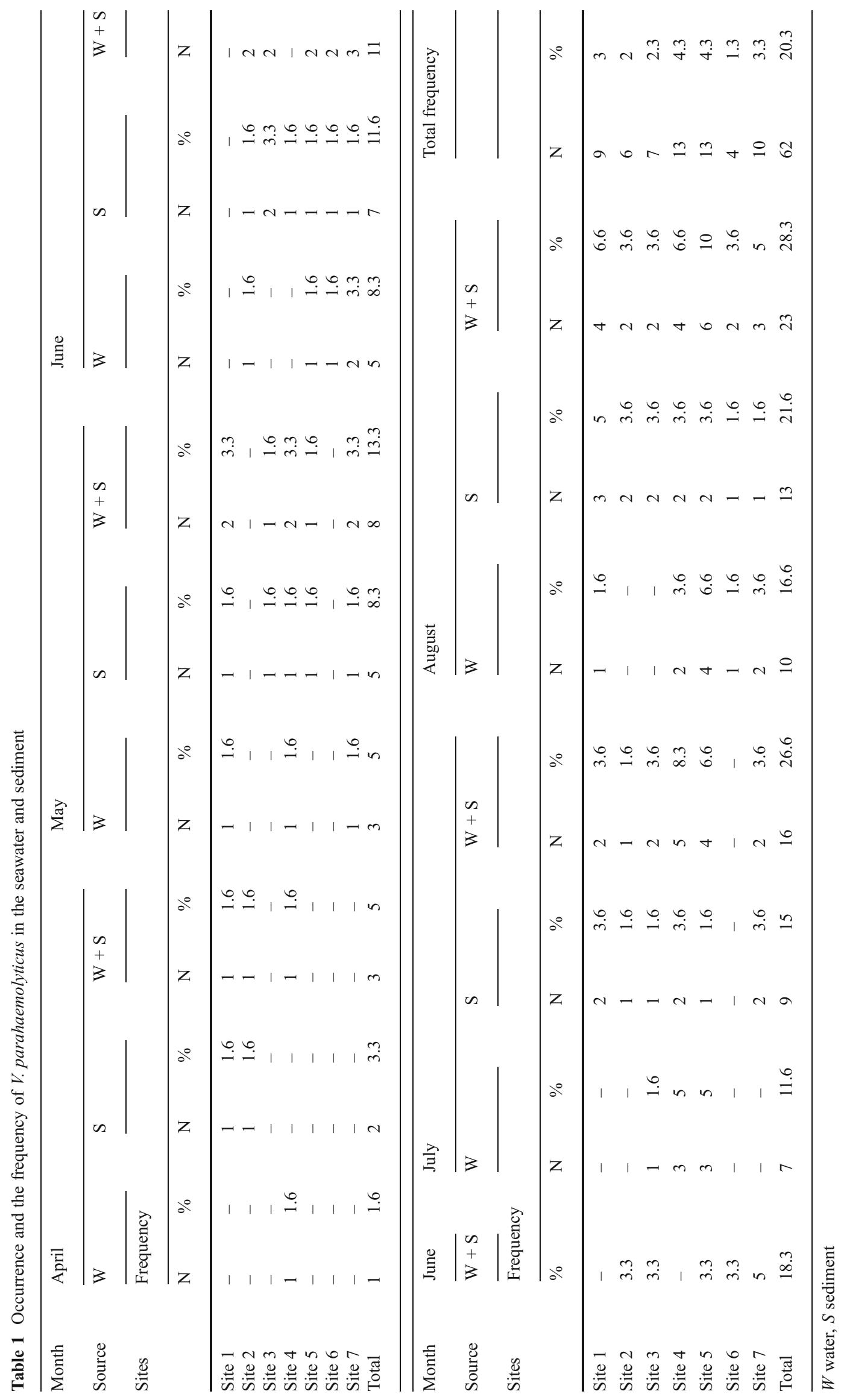


The temperature of the seawater ranged from 10 to $15{ }^{\circ} \mathrm{C}$ during the sampling period. Salinity was highest in summer (19 ppt), whereas the minimum levels were recorded during the spring ( $2 \mathrm{ppt})$. The average salinity was $10.5 \mathrm{ppt}$ during the sampling period.

The highest prevalence of $V$. parahaemolyticus was detected at sampling sites $4(4.3 \%)$ and 5 (4.3\%). Of the 62 strains isolated, $26(8.3 \%)$ were obtained from seawater samples and $36(12 \%)$ from sediments. Only three strains (4.83\%) showed hemolytic activity in Wagatsuma agar. Only two of the 62 strains $(2.53 \%)$ amplified the 250 -bp $t d h$ gene fragment, which correlated with positive hemolytic activity. The trh gene fragment was amplified in four (5.06 \%) of the strains analyzed.

\section{Discussion}

In the present study, we demonstrated the presence of $V$. parahaemolyticus in $20.3 \%$ of the seawater and sediment samples analyzed. This study was the first research to investigate the isolation and distribution of this pathogen in the southern coast of the Caspian Sea. Cabrera-Garcia et al. (2004) reported that $15 \%$ of the seawater samples contained V. parahaemolyticus. This pathogen has also been isolated in Canada (Kelly and Stroh 1988), France (Hervio-Heath et al. 2002), Asia (Alam et al. 2002), and the USA (DePaola et al. 2003). In the present study, of the 62 strains isolated, 26 (8.3\%) were obtained from seawater samples and 36 (12\%) from sediments. VelazquezRoman et al. (2012) have reported that of the 144 strains isolated, $35 \%$ was obtained from seawater samples and $16 \%$ from sediment. Thus, it is speculated that the observed prevalence may also be produced by seasonal variation of the $V$. parahaemolyticus population due to salt and oxygen concentrations, interactions with the plankton, the presence of sediment, and the organic matter in the suspension, fish, and seafood. In one study, it was observed that the maximum probability of $V$. parahaemolyticus detection was around 25 ppt salinity (Martinez-Urtaza et al. 2008). The other reason for the low prevalence of $V$. parahaemolyticus in the southern coast of the Caspian Sea (the average salinity is $10.5 \mathrm{ppt}$ ) is its lower salinity than other seas. The distribution of $V$. parahaemolyticus in the marine environments is known to be related to the water temperatures. Studies have shown that the organism was rarely detected in seawater until water temperatures rose to $15^{\circ} \mathrm{C}$ or higher. Ecological study of V. parahaemolyticus in the Chesapeake Bay of Maryland (USA) found that the organism survived in sediment during the winter and was released from sediment into water column when water temperatures rose to $14{ }^{\circ} \mathrm{C}$ in late spring or early summer (Kaneko and Colwell 1978). The isolation rate of $V$. parahaemolyticus was high $(28.3 \%)$ in August because a higher rate of evaporation results in high salinity. In one study, it was observed that only two pathogenic $V$. parahaemolyticus were confirmed in environmental samples. The extremely low presence of pathogenic populations of $V$. parahaemolyticus in environmental samples is a constant characteristic in most of the investigations carried out in different regions of the world (Martinez-Urtaza et al. 2008). The results of current investigation are consistent with previous reports. We observed positive $t d h$ gene amplification in two of the 62 strains analyzed, which was correlated with the positive hemolytic activity in Wagatsuma agar $\left(\mathrm{KP}^{+}\right)$. Virtually, all clinical isolates of $V$. parahaemolyticus are $\mathrm{KP}^{+}$, whereas only $1-2 \%$ of environmental strains are $\mathrm{KP}^{+}$(Drake et al. 2007). This implies that there is a source of human fecal contamination in the seawater and sediment of the southern coast of the Caspian Sea. This information may be important for preventing sanitary problems that may affect the health of the population. In conclusion, this study provided new information on the abundance of $V$. parahaemolyticus in seawater and sediment samples in the southern coast of the Caspian Sea. The data presented in the present study show the presence of pathogenic $V$. parahaemolyticus and suggest the need for a study of such organism in seafood in the Caspian Sea.

Open Access This article is distributed under the terms of the Creative Commons Attribution License which permits any use, distribution, and reproduction in any medium, provided the original author(s) and the source are credited.

\section{References}

Alam MJ, Tomochika KI, Miyoshi SI et al (2002) Environmental investigation of potentially pathogenic Vibrio parahaemolyticus in the Seto-Inland Sea, Japan. FEMS Microbiol Lett 208:83-87

Bisha B, Simonson J, Janes M et al (2012) A review of the current status of cultural and rapid detection of Vibrio parahaemolyticus. Int J Food Sci Technol 47:885-899

Broberg CA, Calder TJ, Orth K (2011) Vibrio parahaemolyticus cell biology and pathogenicity determinants. Microbes Infect 13:9921001

Cabrera-Garcia ME, Vazquez-Salinas C, Quinones-Ramirez EI et al (2004) Serologic and molecular characterization of Vibrio parahaemolyticus strains isolated from seawater and fish products of the Gulf of Mexico. Appl Environ Microbiol 70:6401-6406

Canizalez-Roman A, Flores-Villasenor H, Zazueta-Beltran J et al (2011) Comparative evaluation of a chromogenic agar mediumPCR protocol with a conventional method for isolation of Vibrio parahaemolyticus strains from environmental and clinical samples. Can J Microbiol 57:136-142

Colakoglu FA, Sarmasik A, Koseoglu B (2006) Occurrence of Vibrio spp. and Aeromonas spp. in shellfish harvested off Dardanelles cost of Turkey. Food Control 17:648-652

DePaola A, Nordstrom JL, Bowers JC et al (2003) Seasonal abundance of total and pathogenic Vibrio parahaemolyticus in Alabama oysters. Appl Environ Microbiol 69:1521-1526 
Drake SL, DePaola A, Jaykus LA (2007) An overview of Vibrio vulnificus and Vibrio parahaemolyticus. Compr Rev Food Sci Food Safe 6:120-144

Hayat MZ, Kassu A, Mohammad A et al (2006) Isolation and molecular characterization of toxigenic Vibrio parahaemolyticus from the Kii Channel, Japan. Microbiol Res 161:25-37

Hervio-Heath D, Colwell RR, Derrien A et al (2002) Occurrence of pathogenic vibrios in coastal areas of France. J Appl Microbiol 92:1123-1135

Kaneko T, Colwell RR (1978) The annual cycle of Vibrio parahaemolyticus in Chesapeake Bay. Microb Ecol 4:135-155

Kelly MT, Stroh EMD (1988) Temporal relationship of Vibrio parahaemolyticus in patients and the environment. J Clin Microbiol $26: 1754-1756$

Martinez-Urtaza J, Lozano-Leon A, Varela-Pet J et al (2008) Environmental determinants of the occurrence and distribution of Vibrio parahaemolyticus in the Rias of Galicia, Spain. Appl Environ Microbiol 74:265-274

Nair GB, Ramamurthy T, Bhattacharya SK et al (2007) Global dissemination of Vibrio parahaemolyticus serotype O3:K6 and its serovariants. Clin Microbiol Rev 20:38-48
Okuda J, Ishibashi M, Abbott SL et al (1997) Analysis of the thermostable direct hemolysin (TDH) gene and the $t d h$-related hemolysin $($ trh $)$ genes in urease-positive strains of Vibrio parahaemolyticus isolated on the West Coast of the United States. J Clin Microbiol 35:1965-1971

Pal D, Das N (2010) Isolation, identification and molecular characterization of Vibrio parahaemolyticus from fish samples in Kolkata. Eur Rev Med Pharmacol Sci 14:545-549

Tada J, Ohashi T, Nishimura N et al (1992) Detection of the thermostable direct hemolysin gene $(t d h)$ and the thermostable direct hemolysin-related hemolysin gene (trh) of Vibrio parahaemolyticus by polymerase chain reaction. Mol Cell Probes 6:477-487

Velazquez-Roman J, Leon-Sicairos N, Flores-Villasenor H et al (2012) Association of pandemic Vibrio parahaemolyticus O3:K6 present in the coastal environment of Northwest Mexico with cases of recurrent diarrhea between 2004 and 2010. Appl Environ Microbiol 78:1794-1803

Yeung PS, Boor KJ (2004) Epidemiology, pathogenesis, and prevention of foodborne Vibrio parahaemolyticus infections. Foodborne Path Dis 1:74-88 